\title{
Acquisition of Case System in Romani Language
}

\section{Овладение падежной системой в ромском языке}

\author{
Hristo Kyuchukov \\ Dr. in Pedagogy, \\ Professor
}

Христо Кючуков

доктор педагогических наук, профессор

E-mail: hkyuchukov@gmail.com

orcid.org/0000-0002-1965-8908

University of Silesia, Poland

$\triangle 12$, Bankowa Str., Katowice, 40-007
Селезский университет в Катовище, Польша

ул. Банковая, 12, Катовице, 40-007

Original manuscript received May 04, 2019

Revised manuscript accepted September 15, 2019

\begin{abstract}
Introduction. The paper presents observations of the author on acquisition of case markers in the Romani language of two Roma children from Bulgaria. This is the first study ever done on acquisition of case system of Romani by children in their natural environment. The study is done in one of the biggest Roma settlement of Bulgaria in the city of Sofia. Romani being a new-Indian language has some features from the Indian languages but also adapted some features from some European languages. It has the ability to express one and the same idea either with a preposition or with a case marker.
\end{abstract}

Methods. The author uses the longitudinal observation of the children in their natural environment, where a woman - representative of the community, was trained to audio record the interviews between parents, family members, community members and the children. This method is known from other studies in field of sociolinguistics and psycholinguistics (Labov, 1973)

Results. The study is investigating what is used more frequently by the children prepositions or case markers. For this purpose, the utterances of the parents and the children with case markers and with the prepositions have been analyzed. It was found that in the age between 1 to 2 parents and respectively their children use more 
case markers. In the age from 2 to 3 children use more prepositions. It seems that Roma children need more experience with the language in order to connect the case marker with the function of the preposition in the Romani language.

Key words: case markers, prepositions, Romani language, acquisition.

\section{Введение}

В исследованиях по овладению языком в последние десятилетия основное внимание уделяется сложным грамматическим категориям и тому, как они изучаются в разных языках. Одним из направлений, исследуемых лингвистами, является приобретение семантического значения различных грамматических категорий, таких как падежные окончания и такой части речи как предлог. Ряд публикаций таких авторов, как M. Bowerman (1973), B. MacWhinney (1978), S. Choi (2015), D. Slobin (1982), A. Aksu-Koç (1988) сыграли важную роль в привнесении новых знаний о процессе овладения такими языками, как английский, финский, венгерский, испанский, корейский и турецкий.

Ромский язык - это один из языков, который не был достаточно исследован. Такие авторы, как Z. Reger Регер (1987) и J. BerakoGleason (1992), более исследовали приобретение прагматических аспектов языка, чем саму грамматику. Н. Kyuchukov (1999a, b; 2007) провел исследование по овладению ромским языком, чтобы понять, как приобретаются понятия и знания по фонологии, морфологии и синтаксисе, но все же этого недостаточно, чтобы осознать, как дети рома получают знания о таких грамматических категориях как предлоги и падежные маркеры.

В последние годы ряд авторов опубликовали статьи о необходимости проверки знаний ромских детей по ромской грамматике. Для психолингвистов очень важно знать, как ромские дети изучают различные грамматические категории (Kyuchukov, Ushakova \& Yashina, 2019); Kyuchukov \& Villiers, 2018; Kyuchukov, Samko \& Kopcanova, 2017; Kyuchukov, Villiers \& Tabori, 2017; New, Kyuchukov \& de Villiers, 2017).

С другой стороны, в своей классической работе (Bowerman \& Choi, 2001) отметили, что при изучении спонтанной речи 
англоязычных и корейскоязычных детей в возрасте от 1 до 3 лет было установлено, что дети начинают продуктивно использовать предлоги в возрасте между 16 и 20 месяцами.

Согласно M. Schoenenberger, M. Royhweiler, F. Sterner (2012), немецкие одноязычные дети развивают знания о системе падежей существительных, переносимых определителями, после 2 лет. G. Szahun (2004) сравнивает нормально развивающихся детей с детьми, у которых есть проблемы со слухом и овладении падежными окончаниями в немецком языке. Но в немецком языке система маркировки падежа не столь прозрачна, как в языках подобно турецкому, так как она объединена числовой и гендерной информацией (Slobin, 1982). Дети используют семантическую и синтаксическую информацию, предоставленную глаголом, для создания структуры события (Özge et al., 2016).

Интересна маркировка падежей в языке хинди. В. Narasimhan (2005) провел исследование с 3 детьми, говорящими на этом языке в возрасте 1.7, 3 и 9 лет, обращая внимание на то, как они изучают падежную систему языка. Предполагалось, что дети, полагающиеся на широкое или узкое толкование агенса, будут чрезмерно растягивать маркировку эргативного падежа для агентивных участников переходных несовершенных действий и/или непереходных действий. Полученные результаты свидетельствуют о том, что дети никогда не расширяют маркировку падежа от переходных к непереходным ролевым аргументам.

\section{Система падежей в ромском языке}

Ромский язык относится к новоиндийским языкам. Согласно В. Фридману (Friedman, 1991: 86), «рома устранили большую часть унаследованной индоевропейской системы склонения санскрита и пракрита, сохранив только номинативный, винительный и звательный падежи и заменив другие падежи сериями постпозиций, добавленных к основе. Однако в отличие от других индийских языков ромский язык не имеет комплекса отдельно стоящих послелогов. Напротив, он имеет только пять аффиксов, которые более или менее соответствуют по функциям пяти санскритским падежам, которые они заменили (дательный, местный (локатив), родительный, отделительный (аблатив), творительный»). Косвенные падежи ромского языка соответствуют послелогам западно- 
индийских языков, таких как хинди, непальский, панджаби, синдхи, гуджарати и маратхи. Однако Фридман считает, что ромский язык следует рассматривать в его собственных условиях, так как он отличается от остальных современных индийских языков, потому что языки Индии все постпозиционные а ромский язык является предложным.

Согласно Igla (1997) предлоги в ромском языке «управляют именительным падежом с существительными и местным падежом с местоимениями». К. Костов и Д. Илиев (2004), описывая софийскоэрлийский диалект, заявили, что некоторые косвенные падежи в этом диалекте могут быть представлены через предлоги.

Глаголы в ромском языке требуют определенных падежей (как и в других новых индийских языках), а также они могут использоваться с предлогами. Именной падеж данного языка это именительный. Винительный и дательный падежи, которые также были именными падежами под влиянием европейских контактных языков, оказываются косвенными падежами. Другими косвенными падежами в ромском языке являются отделительный (аблатив), местный (локатив) и родительный. Здесь приведены некоторые примеры предложений на ромском языке, показывающие использование предлога и падежного маркера.

\begin{tabular}{|c|c|}
\hline Винительный & $\begin{array}{l}\text { 1) O čhavo džal karig e roma } \\
\text { Мальчик идет к мужчинам. (именит. падеж) } \\
\text { 2) O čhavo dikhel e romen } \\
\text { Мальчик смотрит на мужчин. (винит. падеж) }\end{array}$ \\
\hline Дательный & $\begin{array}{l}\text { 3) O 3) O čhavo del ki chaj luludi } \\
\text { Мальчик дает девочке цветок. (именит. падеж) } \\
\text { O 4)O čhavo del e chajake luludi } \\
\text { Мальчик дает девочке цветок. (дательн. падеж) }\end{array}$ \\
\hline Аблатив (творительный) & $\begin{array}{l}\text { 5) O čhavo avel andar o kher } \\
\text { Мальчик приходит из дома. (именит. падеж) } \\
\text { 6) O čhavo avel kherestar } \\
\text { Мальчик приходит из дома. (аблатив) }\end{array}$ \\
\hline Локатив(местный) & $\begin{array}{l}\text { 7) Me sijom ando kher. } \\
\text { Я в доме. (именит. падеж) } \\
\text { 8) O lil si mande } \\
\text { Книга со мной. (локатив) }\end{array}$ \\
\hline Творительный & $\begin{array}{l}\text { 9) O rom džal grastesa. } \\
\text { Мужчина идет с лошадью. (творит. падеж) }\end{array}$ \\
\hline Родительный & $\begin{array}{l}\text { 10) Ačhiljom bi love. } \\
\text { Я остался без денег. (именит. падеж) } \\
\text { 11) O gad si e čhavesko } \\
\text { Рубашка принадлежит мальчику. (родит. падеж) }\end{array}$ \\
\hline
\end{tabular}


Дети рома участвуют в семейных дискуссиях. Ромская культура, являющаяся устной культурой, дает возможность детям с самого раннего возраста участвовать в различных языковых мероприятиях, общаться с различными членами семьи разного возраста, используя для этого различные стили. В повседневной жизни они знакомятся с обеими формами грамматического выражения и при этом используют предлоги и используют падежные маркеры.

Moе предположение заключается в том, что поскольку ромский язык является языком предложным, дети сначала изучат предлоги, а затем они приобретут знания о падежных маркерах. Ромский язык имеет две системы -одна использует предлоги и существительные в именительном падеже, а вторая падежную маркировку существительных. Это исследовательский вопрос, на который я пытаюсь ответить здесь: как эти системы возникают у детей, изучающих ромский язык?

\section{Процедура исследования}

Участники исследования. Исследованы лонгитюдиальные данные девочки и мальчика в возрасте 1 год и 3 года. Это дети из ромских семей с низким уровнем социоэкономического статуса, оба из самого большого поселения цыган типа гетто в Софии (Болгария). Для измерения социоэкономического статуса семей был выяснен образовательный статус родителей, а также их ежемесячный доход. Доход на одного члена семьи оказался ниже прожиточного минимума, принятого в Болгарии.

Одна женщина из общины Рома прошла подготовку по сбору данных. Процесс ее обучения известен из публикаций В. Лабова (Labov, 1973). Таким образом, она являлась участником общения с родителями и детьми и частью их языкового окружения. Раз в месяц она навещала семьи и проводила с ними время в их естественной домашней обстановке. Она фиксировала взаимодействие детей с первичными воспитателями (членами семьи) и другими собеседниками (посетителями, домашней прислугой) в естественных и полу естественных условиях, которые включали игру с игрушками, чтение книг, спонтанную игру и время приема пищи. Исследователи участвовали во взаимодействии там, где это казалось естественным 
и уместным. В конце примерно двухлетнего исследования было записано в общей сложности 137 часов разговоров. Длительность каждого разговора от часа до полутора часов.

\section{Кодирование}

Все высказывания взрослых и детей с предлогами и/или с падежными маркерами были идентифицированы и подсчитаны. Предлоги и падежная система ромского языка приведены в следующих таблицах, созданных автором (Табл. 1, 2).

Таблица 1. Предлоги софийско-эрлийского диалекта

\begin{tabular}{ll}
\hline \multicolumn{1}{c}{ Падеж } & \multicolumn{1}{c}{ Предлоги } \\
\hline Именительный & - \\
Винительный & ko, ki, karig, mamuj, po \\
Дательный & ašal,ko, ki \\
Творительный (аблатив) & andar, katar, tar \\
Местный (локатив) & avrjal, anglal, telal, maškar, upral, palal, katar, an, \\
Творительный (инструментальный) & ando, ande, paš, pašal dži, maškar, mamuj, ko \\
Родительный & - \\
Звательный & bi \\
\hline
\end{tabular}

Таблица 2. Падежная система ромского языка

\begin{tabular}{lllll}
\hline Падежс & rom $-m . s g$. & roma $-m . p l$. & luludi-f. sg & luludja $-f . p l$. \\
\hline Именительный & rom & roma & luludi & luludja \\
Винительный & romes & romen & luludi & luludja \\
Дательный & romeske & romenge & luludjake & luludenge \\
Творительный & romestar & romendar & luludjatarle & luludjatar \\
Местный & romeste & romende & luludjate & luludjate \\
Творительный & romesa & romensa & luludjasa & luludjensa \\
Родительный & romeskoro & romengo & luludjako & luludengo \\
Звательный & roma! & romalen! & luludije! & luludjalen! \\
\hline
\end{tabular}

Я сравниваю использование предлогов/падежных маркеров взрослыми в речи, направленной к детям, и воспроизведение детьми предлогов/падежных маркеров. Для этого я анализирую 500 высказываний взрослых и 500 высказываний детей второго года жизни и 500 высказываний детей на третьем году жизни. 500 высказываний были взяты из базы данных автора по принципу случайного выбора. 500 высказываний родителей отличаются от 500 
высказываний детей в возрасте от 1 года до двух и отличаются от высказываний детей в возрасте от 2 до 3 лет.

\section{Результаты}

Ниже представлен анализ данных, полученных в исследовании речи девочки Сали и мальчика Атанаса. Одновременно я анализирую язык родителей. Таблица представляет язык детей и родителей из базы данных. Результаты будут поделены на две возрастные группы: второй год жизни (возраст от года до двух) и третий год (от двух до трех лет).

\section{Возраст от года до двух}

Результаты этого периода представлены в следующих таблицах (Табл. 3, 4).

Таблица 3. Количество падежных маркеров, используемых взрослыми и детьми

\begin{tabular}{lcccc}
\hline Падежс & Взрослый & Атанас & Взрослый & Сали \\
\hline Именительный & 34 & 18 & 25 & 14 \\
Винительный & 19 & 4 & 13 & 2 \\
Дательный & 40 & - & 30 & - \\
Творительный (аблатив) & - & - & 4 & - \\
Местный (локатив) & - & - & 2 & - \\
Творительный & 1 & - & - & - \\
Родительный & 2 & - & 1 & - \\
Звательный & 21 & 20 & 12 & 7 \\
\hline
\end{tabular}

Из таблицы 3 видно, что речь взрослых с Сали богаче, чем с Атанасом. Разговаривая с Сали, взрослые используют более разнообразные падежные маркеры. Они используют не только творительный падеж.

Таблица 4. Количество предлогов, используемых взрослыми и детьми

\begin{tabular}{lcccc}
\hline Падежс & Взрослый & Атанас & Взрослый & Сали \\
\hline Именительный & - & - & - & - \\
Винительный & - & - & - & - \\
Дательный & ki 2 & - & ko $1 ;$ ki 1 & - \\
Творительный (аблатив) & - & - & tar 3 & - \\
Местный (локатив) & katar 1; ko 1 & - & an 2 & - \\
\hline
\end{tabular}


Творительный

Родительный

Звательный

$\begin{array}{lll}- & - & - \\ - & - & - \\ - & - & -\end{array}$

Таблица 4 показывает, что в этом периоде взрослые, общаясь с детьми, используют похожее, но очень ограниченное количество предлогов. Используются предлоги только в дательном, творительном (аблатив) и местном падежах.

\section{Оиибки в использовании падежнных маркеров.}

При общении с детьми видны некоторые погрешности в использовании падежных маркеров; так мама Атанаса использует неправильный падежный маркер для винительного и дательного падежей.

Взрослый: Ka trades li o grast (e grastes) [Собираешься ехать на лошади?] - винительный.

Взрослый: De mande (mange) [дай мне] - дательный.

\section{Возраст от 2 до 3 лет}

Таблица 5. Количество падежных маркеров, используемых взрослыми и детьми

\begin{tabular}{lcccc}
\hline Падежс & Взрослый & Атанас & Взрослый & Сали \\
\hline Именительный & 48 & 23 & 57 & 24 \\
Винительный & 34 & 13 & 40 & 18 \\
Дательный & 58 & 26 & 70 & 27 \\
Творительный (аблатив) & 6 & 2 & 10 & 6 \\
Местный (локатив) & - & - & 13 & 7 \\
Творительный & 17 & 8 & 27 & 12 \\
Родительный & 28 & 11 & 18 & 3 \\
Звательный & 33 & 30 & 8 & 8 \\
\hline
\end{tabular}

Таблица 5 показывает, что использование падежных маркеров обоими детьми в этом возрасте становится практически одинаковым, и они постепенно овладевают ими. Падежные маркеры быстро увеличиваются в количестве в этом возрасте и по частоте использования соответствуют образцам взрослого. В конечном счете, предлоги появляются, хотя и менее часто, чем предложные окончания. Как показано в таблице 6, Сали более успешна, чем Атанас в использовании разнообразия предлогов, соответствуя в этом взрослым. 
Овладение падежной системой в ромском языке

Таблица 6. Количество предлогов, используемых взрослыми и детьми

\begin{tabular}{lcccc}
\hline Падежс & Взрослый & Атанас & Взрослый & Сали \\
\hline Именительный & - & - & - & - \\
Винительный & ko 4 & - & ki 3 & ki 3 \\
Дательный & ki 6 & ki 4 & ki 6 & ki 2 \\
Творительный (аблатив) & & - & $\operatorname{tar} 3$ & $\operatorname{tar} 2$ \\
Местный (локатив) & kо 4 & ko 2 & ži 3; ko 4 & ko 3 \\
Творительный & - & - & - & - \\
Родительный & - & - & - & - \\
Звательный & - & - & - & - \\
\hline
\end{tabular}

Представляется, что для использования предлогов детям необходимо большее знание языка и более высокое когнитивное развитие. Это умение приходит во время третьего года жизни, когда дети уже умеют связывать два и три слова в предложениях.

Представляем примеры предложений.

Взросльй: Kaske obadines tut ko telefonni? [Кому ты звонишь по телефону?] - дательный.

Сали (2; 4) ko tatis [папе] - дательный

Такие предложения могут быть созданы тогда, когда ребенок уже имеет достаточное знание по грамматике.

\section{Обсуждения и выводы}

Мои предположения о том, что ромские дети выучат предлоги, а затем падежные маркеры не подтвердились. Проведенное здесь исследование показывает, что дети рома сначала изучают падежные маркеры на цыганском языке, и только позднее они приобретают предлоги. В целом правильное использование падежных маркеров для любого языка гораздо сложнее, но, похоже, для детей, говорящих на ромском языке, это не так. По-видимому, для детей Рома, чтобы приобрести понятие предлогов и понять их функции, нужно больше опыта работы с языком, а также более высокие когнитивные процессы, чтобы связать, например, падежный маркер$\boldsymbol{k} \boldsymbol{e}$ (для дательного) с предлогом $\boldsymbol{k o}$. Все эти знания дети получают от матерей и родственников, используя разные стили в общении с ними. Большую роль играет также устная культура Рома. Слушание народных сказок, песен, шуток, дразнилок и других фольклорных жанров в повседневной жизни помогает детям освоить сложные 
грамматические категории. Сравнивая результаты спонтанной речи детей рома с существующими публикациями о приобретении семантического значения предлогов (Bowerman \& Choi, 2001), можно придти к выводу, что данные, полученные в исследовании, открывают новый взгляд на то, как семантическое значение некоторых грамматических категорий приобретается детьми из разных культур.

\section{References}

Aksu-Koç, A. (1988). The Acquisition of Aspect and Modality: The Case of Past Reference in Turkish. Cambridge. https://doi.org/10.1017/CBO9780511554353

Berako-Gleason, J. (1992). Language Acquisition and Socialization. University Lecture. Boston.

Bowerman, M. (1973). Structural relationships in children's utterances: Semantic or syntactic? In T.E. Moore (Ed.), Cognitive Development and the Acquisition of Language (pp. 197-213). NY. https://doi.org/10.1016/B978-0-12-505850-6.50015-3

Bowerman, M., \& Choi, S. (2001). Shaping meanings for language: universal and language-specific in the acquisition of special semantic categories. In M. Bowerman \& S.C. Levinson (Eds.), Language Acquisition and Conceptual Development (pp. 475-511). Cambridge. https://doi.org/10.1017/ CBO9780511620669.018

Choi, S. (1993). Development of locative case markers in Korean. Japanese Korean Linguistics, 2, 205-222.

Friedman, V. (1991). Case in Romani: Old grammar in new affixes. Journal of the Gypsy Lore Society 5.1(2), 85-102.

Igla, B. (1997). The Romani dialect of the Rhoropes. In Y. Matras, P. Bakker \& H. Kyuchukov (Eds), The Typology and Dialectology of Romani (pp. 147-159). Amsterdam: John Benjamins Publishing Company. https://oi.org/10.1075/ cilt.156.09igl

Kostov, K., \& Iliev, D. (2004). Romska gramatika [Romani grammar]. Sofia: Tilia.

Kyuchukov, H., Ushakova, O., \& Yashina, V. (2019) Are the Roma children «mentally retarded» if they do not know the syntax of their second language? Clinical social work and health intervention, 10(2), 62-70. https://doi.org/10.22359/ cswhi_10_2_09

Kyuchukov, H., \& de Villiers, J. (2018). Language Complexity, Narratives and Theory of Mind of Romani Speaking Children. East European Journal of Psycholinguistics, 5(2), 16-31.

Kyuchukov, H., Samko, M., \& Kopcanova, D. (2017). Knowledge of Romani language grammar. Psychology in Russia: State of the Art, 10(4), 76-85. https:// doi.org/10.11621/pir.2017.0407

Kyuchukov, H., de Villiers, J., \& Tabori, A. (2017). Why Roma children need language assessments in Romani? Psychology of Language and Communication, 21(1), 215-243. https://doi.org/10.1515/plc-2017-0011

Kyuchukov, H. (1999). Early acquisition of Romani (Gypsy) language. In M. de G. Pinto, J. Veloso \& B. Maia (Eds.), Proceedings from the $5^{\text {th }}$ International 
Congress of the International Society of Applied Psycholinguistics (pp. 329-337). Porto: Porto University Press.

Kyuchukov, H. (2007). How do children learn Romani syntax? In P. Ilieva-Baltova \& K. Petrova (Eds.), Psycholinguistic Studies (pp. 271-281). Sofia: Riva Publishers. Kyuchukov, H. (1999a). Acquisition of Romani morphology. Grazer Linguistischen Studien, 51, 83-94.

Kyuchukov, H. (2003). Kratko opisanie na romskiya ezik v Bulgaria [Short description of Romani language in Bulgaria]. Sofia: Delfi [in Bulgarian].

Labov, W. (1973) Language in the Inner City. Studies in the Black English Vernacular. University of Pennsylvania Press.

MacWhinney, B. (1978). The acquisition of morphophonology. Monographs of the Society for Research in Child Development, 43(1/2), 1-123. https://doi. org/10.2307/1166047

Narasimhan, B. (2005). Splitting the notion of 'agent': case-marking in early child Hindi. Journal of Child Language, 32, 787-803. https://doi.org/10.1017/ S0305000905007117

New, B., Kyuchukov, H., \& de Villiers, J. (2017) «We do not speak Gypsy here»: Minority language policies in Europe. Journal of Language and Cultural Education, 5(2), 1-24. https://doi.org/10.1515/jolace-2017-0015

Özge, D., Kornfilt, J., Münster, K., Knoeferle, P., Küntay, A., \& Snedeker, J. (2016). Predictive Use of Case Markers in German Children. Proceedings of the $40^{\text {th }}$ Annual Boston University Conference on Language Development (pp. 299-303). Somerville, MA: Cascadilla Press.

Reger, Z. (1986). The functions of imitation in child language. Applied Psycholinguistics, 7, 323-352. https://doi.org/10.1017/S0142716400007712

Schönenberger, M., Rothweiler, M., \& Sterner, F. (2012). Case marking in child L1 and in earl child L2 German. Multilingual individuals and multilingual societies (pp. 3-22). Amsterdam. https://doi.org/10.1075/hsm.13.03sch

Slobin, D. (1982). Universal and particular in the acquisition of language. In E. Wanner \& L. Gleitman (Eds.), Language Acquisition: The State of the Art (pp. 128-172). Cambridge: Cambridge University Press.

Szahun, G. (2004). Learning by ear: on the acquisition of case and gender marking in German speaking children with normal hearing and with cochler implants. Journal of Child language, 31(1), 1-30. https://doi.org/10.1017/S0305000903005889

\section{АННОТАЦИЯ}

Цель. В статье представлены наблюдения автора над процессом овладения падежными маркерами в ромском языке двумя детьми рома, проживающими в Болгарии. Это первое исследование по овладению падежной системой в ромском языке детьми, проведенное в естественных условиях. Исследование осуществлено в одном из самых больших ромских поселений в Болгарии в городе София. Ромский язык, будучи новоиндийским языком, имеет определенные черты индийских языков, но в тоже время в нем произошла адаптация некоторых черт европейских языков. Язык способен одну и ту же мысль выразить с помощью предлога или с помощью падежного маркера.

Процедура исследования. Автор использует лонгитюдинальное наблюдение за детьми в их естественной обстановке. В ходе исследования женщина- 
представитель общины, обученная заранее, производила аудио записи бесед между родителями, членами семей, членами общины и детьми. Этот метод известен из других исследований социолингвистики и психолингвистики (Labov, 1973). Автор ищет ответ на вопрос, что используется детьми чаще предлоги или падежные маркеры. Для этой чели проводятся наблюдения над высказываниями с падежными маркерами и с предлогами родителей и детей.

Результаты. В ходе каждодневного общения между родителями и детьми, было установлено, что в возрасте от 1 года до 2 лет родители, $и$ соответственно дети, больше используют падежные маркеры. В возрасте от 2 до 3-х лет дети больше пользуются предлогами. Исследование также показывает, что ромским детям необходимо больще практики с языком, чтобы соединить падежный маркер с функцией предлога в ромском языке.

Ключевые слова: падежные маркеры, предлоги, ромский язык, овладение.

\title{
Кючуков Христо. Оволодіння відмінковою системою в румунській мові
}

\begin{abstract}
АНОТАЦІЯ
Мета. У статті представлені спостереження автора над процесом оволодіння відмінковими маркерами румунської мови двома дітьми рома, які проживають у Болгарії. Це перше дослідження з оволодіння відмінковою системою румунської мови дітьми, проведене в природних умовах. Дослідження здійснено в одному з найбільших ромських поселень в Болгарії - в місті Софрія. Румунська мова, будучи новоіндійською мовою, має певні риси індійських мов, але в той же час в ній відбулася адаптація деяких рис європейських мов. Мова здатна одну й ту ж думку висловити за допомогою прийменника або з допомогою відмінкового маркера.
\end{abstract}

Процедура дослідження. Автор використовує лонгитюдні спостереження за дітьми в їхньому природному середовищі. В ході дослідження жінкапредставник громади, навчена заздалегідь, здійснювала аудіозаписи бесід між батьками, членами сімей, членами громади й дітьми. Цей метод відомий 3 інших досліджень сочіолінгвістики й психолінгвістики (Labov, 1973). Автор шукає відповідь на запитання, що використовується дітьми частіше - прийменники або відмінкові маркери. 3 чією метою проводяться спостереження над висловлюваннями з відмінковими маркерами і з прийменниками батьків і дітей. Результати. В ході щоденного спілкування між батьками й дітьми, було встановлено, що у віці від 1 року до 2 років батьки, й відповідно діти, більше використовують відмінкові маркери. У віці від 2 до 3-х років діти більше користуються прийменниками. Дослідження також показує, що ромським дітям необхідно більще практики з мовою, щоб з'єднати відмінковий маркер з функцією прийменника в ромській мові.

Ключові слова: відмінкові маркери, прийменники, ромська мова, оволодіння. 